\title{
A TRAVÉS DEL CRISTAL: RELATIVISMO Y DESHUMANIZACIÓN DE LA ALTERIDAD
}

\author{
SEEING THROUGH A WALL OF GLASS: RELATIVISM AND DEHUMANIZATION
}

\author{
Claudia Compte Vives \\ Universitat de València (España)
}

Recibido: 20-05-2012

Aceptado: 26-06-2012

\begin{abstract}
Resumen: Este artículo trata de poner en cuestión la idea de que la forma de mirar la alteridad que fomentan algunas versiones del relativismo moral puede inhabilitar los mecanismos deshumanizadores que suelen desencadenarse en un marco universalista. Tras presentar un tipo de experiencia que da sentido a la posición relativista y exponer la articulación contemporánea de la posición elaborada por Gilbert Harman, trato de mostrar puede servir de trasfondo teórico a ciertas actitudes y prácticas que deshumanizan al otro.
\end{abstract}

Palabras-clave: alteridad, relativismo moral, deshumanización.

\begin{abstract}
This essay attempts to question the claim that some current versions of moral relativism suggest a way of looking to the alterity that can prevent her dehumanization, as opposed to the kind of outlook raised by universalist approaches. After presenting Gilbert Harman's position as an instance of contemporary relativist theory I aim to point out the ways in which relativism might motivate dehumanizing attitudes and practices towards the other.
\end{abstract}

Key-words: alterity, moral relativism, dehumanization.

\section{Universalismo moral y deshumanización}

Desde la Modernidad hasta nuestros días, la cuestión de qué actitud moral adoptar con respecto a la alteridad ha funcionado como uno de los hilos conductores de la historia de la filosofía. Dos perspectivas, universalismo y relativismo, han ido fraguando en el contexto de este debate; perspectivas que hoy muchos ven como agotando el espectro de posibles elaboraciones de una 
respuesta a la pregunta de cómo situarse moralmente con respecto a aquellos que percibimos como otros.

La forma y la medida en que debe escucharse la voz de aquellos que vemos como "otros" a la hora de actuar se presenta como un desafío filosófico cuando esa voz defiende prácticas y puntos de vista que difieren en un grado sustantivo de los nuestros. La experiencia del conflicto de valores, del choque entre diferentes formas de ver el mundo, es a la vez punto de partida y llegada de cualquier intento de elaborar una respuesta satisfactoria a esta pregunta.

En ocasiones, estos conflictos adoptan formas de expresión violenta. Algunas de estas manifestaciones, como la guerra, la segregación o el genocidio, exigen a los agentes implicados formas de comportamiento que sólo resultan inteligibles en la medida en que dichos agentes adoptan una perspectiva deshumanizadora con respecto a los otros. Abrazar este tipo de perspectiva es lo que permite a un agente ver como moralmente aceptable -incluso requeribleque seres humanos pertenecientes a un grupo diferente sean tratados, en determinadas circunstancias, de forma inhumana.

La relación íntima que existe entre universalismo y deshumanización, ha sido reiteradamente subrayada en la bibliografía antropológica del pasado siglo. Autores con influencias tan diversas como Edward Said o Clifford Geertz, coinciden en señalar que el precio a pagar por la preponderancia del discurso universalista a lo largo de la historia, ha sido la deconstrucción -a menudo literal- de la alteridad ${ }^{1}$. Desde las Cruzadas hasta las recientes invasiones neo-coloniales en Oriente Próximo, el universalismo ha jugado un papel central en la retaguardia de los enfrentamientos violentos entre culturas a lo largo de la historia, demostrado su utilidad a la hora de justificar formas de conceptualización y de trato deshumanizadoras.

La intuición central de la que parte el universalismo moral es que existen hábitos bien establecidos en el seno de algunas comunidades humanas que pueden ser juzgados objetivamente como inmorales. Para el universalista, hay comunidades de seres humanos equivocadas con respecto a ciertas cuestiones de vital importancia. En consecuencia, la forma de vida que estas comunidades han desarrollado partiendo de tales errores es -en algún sentido- deficiente, y la responsabilidad de redirigir su conducta recae sobre aquellos que han desarrollado una comprensión más profunda de la vida buena. Para sostener estas afirmaciones, el universalista se compromete a defender la tesis de que todos los seres humanos comparten un conjunto básico de valores morales; unos estándares universales desde los cuales no sólo acciones individuales sino ritos y costumbres que practican comunidades enteras pueden ser evaluados.

Para entender porqué el acercamiento universalista constituye un sustrato teórico en el que la deshumanización de la alteridad germina con facili-

[1] GEERTZ, "Anti-antirrelativismo", en Los usos de la diferencia, Paidós, 1996, Barcelona, p. 123

THÉMATA. Revista de Filosofía, Nº48 julio-diciembre (2013) pp.: 121-133 doi: 10.12795/themata.2013.i48.10 
dad, es necesario distinguir entre dos construcciones de la posición con consecuencias distintas. Por una parte, hay universalistas que aceptan la idea de que existen comunidades humanas cuyo sistema de valores dista tanto de encajar en los estándares fijados como universales que pueden situarse, en algún sentido, más allá de lo humano. Así, a principios del XVI, gran parte de los colonos españoles percibían a los indios americanos como seres humanos tan alejados de su concepción de lo humano que consideraban erróneo atribuirles plena humanidad.

Este tipo de universalismo exclusivo afronta la oposición de una elaboración más inclusiva de la posición. De acuerdo con ella, ninguna comunidad de seres humanos puede no ser considerada como plenamente humana, a no ser que el observador esté incurriendo en alguna confusión o error perceptivo. Desde este punto de vista, a pesar de las radicales diferencias que puedan identificarse entre dos comunidades, un estudio cuidadoso puede demostrar que todas ellas son humanas en el mismo grado y sentido. Esta perspectiva favorece una definición menos etnocéntrica de la axiología elemental, que tiende a ensancharse para englobar el mayor número de comunidades humanas existentes que sea posible.

Resulta sencillo advertir cómo la primera de las dos articulaciones del universalismo favorece una mirada deshumanizadora hacia el otro. Si la alteridad observada no es humana en la misma medida que lo es el observador, este parece estar en su derecho de reclamar razones adicionales que justifiquen la obediencia ante el imperativo de tratarla como si lo fuera. En tales circunstancias, parece razonable hacer algún tipo de discriminación en la forma de trato hacia el otro que responda al menor grado de humanidad que se le reconoce.

Este tipo de discriminación es más difícil de justificar desde la segunda versión del universalismo. Sin embargo, como el conjunto de valores considerado como definitorio del ámbito humano no puede englobar todos los hábitos y costumbres de todos los grupos existentes, las comunidades pueden considerarse moralmente mejores o peores que otras en función de si sus costumbres concuerdan en mayor o menor medida con los estándares fijados. Así, la historia contemporánea está salpicada de ejemplos de la utilización de juicios que establecen la superioridad moral de unas culturas frente las otras con respecto a estos estándares con el fin de justificar formas de trato deshumanizadoras hacia algunas comunidades.

Así, el rasgo que comparten las dos articulaciones del universalismo moral, clave de su predisposición a servir de transfondo teórico de actitudes y prácticas deshumanizadoras, puede expresarse de la siguiente manera: en ambos casos hay una voz, la voz del "otro", que no es genuinamente escuchada, de forma que no se da un auténtico reconocimiento del otro como interlocutor válido en el proceso de disputa. Esta ausencia de apertura hacia las razones que se elaboran desde la otra perspectiva, se justifica por su carácter defectuo- 
so: son razones elaboradas a partir de errores fundamentales. Por ello, no son razones "para" el nosotros del que formo parte; es decir, aptas para contribuir al proceso de construcción de sentido de mi comunidad.

La identificación de este rasgo de la posición universalista, ha llevado a un creciente número de personas implicadas en este debate -especialmente desde el ámbito de la filosofía moral y la antropología filosófica- a optar por defender alguna de las posibles articulaciones del relativismo. El presupuesto que da sentido a este movimiento reflexivo es que la aproximación a la alteridad desde la concepción relativista inhabilita, de algún modo, los mecanismos deshumanizadores que, en el marco teórico universalista, encuentran un rico sustrato para desarrollarse.

El propósito de esta ponencia es desafiar este presupuesto. A lo largo del texto, se intentará demostrar que la concepción relativista comparte con la universalista el rasgo que hace de esta última un instrumento teórico útil para justificar la adopción de una perspectiva deshumanizadora hacia la alteridad; a saber, la carencia de un auténtico reconocimiento del otro como interlocutor. Por tanto, se defenderá que abrazar una teoría relativista no constituye una forma efectiva de poner trabas a la deshumanización del otro.

\section{Relativismo moral}

Me gustaría empezar presentando la experiencia de la que parten los defensores de la perspectiva relativista a través de un pasaje de $E l$ corazón de las tinieblas. En este pasaje, Marlow, protagonista y narrador de la historia, relata lo que va viendo durante un paseo por una explotación de la Compañía en la que permanece unos días antes de seguir remontando el río Congo en busca de Kurtz. Entre otras, el marinero inglés describe la siguiente escena:

"Llegué por fin a la arboleda con el propósito de caminar a la sombra durante un trecho; pero nada más llegar a los árboles tuve la impresión de haber entrado en uno de los oscuros círculos del Infierno. (...)

Se distinguían varias sombras negras en cuclillas, tendidas, sentadas entre los árboles, apoyadas contra los troncos; se confundían con el terreno, apenas visibles en la penumbra, adoptando todas las formas del dolor, del abandono y la desesperación” ${ }^{2}$

Las palabras de Marlow expresan con belleza la ambivalencia de su percepción: por una parte, lo que ve son "sombras negras" que se confunden con la vasta vegetación de la selva, pero sombras que, de algún modo, se reconocen como objeto del dolor, el abandono y la desesperación. Las figuras no son explícitamente identificadas como personas, pero su humanidad aflora en la descripción que de ellas ofrece el protagonista.

[2] CONRAD, J.; El corazón de las tinieblas, El País: Clásicos del siglo XX, 2002, Madrid, pp. 36-37

THÉMATA. Revista de Filosofía, Nº48 julio-diciembre (2013) pp.: 121-133 doi: 10.12795/themata.2013.i48.10 
La situación ilustra con claridad la ambivalencia entre dos sensaciones aparentemente opuestas que se experimenta en algunas situaciones de contacto con la alteridad: por una parte, la resistencia de la realidad observada a recibir el tipo de mirada distintivo de lo humano; por otro, la necesidad de reconocer su humanidad.

Esta experiencia de escisión entre las dos sensaciones, es central para el relativista, que aspira a mostrar que la inconsistencia entre de ambas experiencias es sólo aparente. Las teorías relativistas parte de la intuición de que la ambivalencia de Marlow no reside en un error de percepción, y tratan de elaborar de un modo convincente la compatibilidad de las dos experiencias en las que la imagen del otro parece escindirse.

Para darle contenido a la imagen relativista, vale la pena presentar la concepción de Hilbert Harman, autor de una de las versiones más sólidas del relativismo moral contemporáneo. La tesis de la que parte este filósofo es que existe una amplia variedad de moralidades -o marcos morales de referencia-, de tal modo que la cuestión de si algo es bueno o malo, justo o injusto, es una cuestión relativa: puede ser lo uno o lo otro en función del marco moral en el que el agente se sitúa ${ }^{3}$.

Harman insiste en que esta es una afirmación puramente lógica sobre la forma de los juicios morales, y utiliza las analogías entre moralidad, sistema legal y lenguaje para ilustrar en qué sentido es $a^{1} i^{4}$. Del mismo modo que el significado de determinada secuencia de sonidos es relativa a un lenguaje o que la licitud de una acción es relativa a un cuerpo de leyes, el carácter moral de una acción es relativo a una moralidad, esto es, a un conjunto determinado de principios conforme a los cuales los miembros de una comunidad se sienten motivados a actuar ${ }^{5}$.

Si este carácter relativo de los juicios no impide a un miembro de una comunidad identificar como moral un juicio dictado desde una moralidad distinta, es porque los juicios morales adoptan una misma forma reconocible independientemente de su contenido. Un elemento central de tal forma es la incorporación del verbo "deber", que capta la relación de obligación que existe entre el agente y una acción. Otro elemento en juego son ciertas actitudes motivacionales que el emisor del juicio presupone que comparte con el agente y con su audiencia. Así, si un sujeto afirma que un agente A debe (moralmente) llevar a cabo la acción X, asume que sus motivos para emitir el juicio pueden ser reconocidos por A como motivos para actuar del modo relevante ${ }^{6}$. Por últi-

[3] HARMAN, G.; "Moral Relativism", Princeton University, 17 Diciembre de 2011, p. 1

[4] HARMAN, G. "Moral Relativism Defended", en Explaining Value and other Essays in Moral Philosophy, Oxford University Press, 2005, Oxford, p. 3-4

[5] HARMAN, G.; "Moral Relativism”, Princeton University, 17 Diciembre de 2011, p. 5

[6] HARMAN, G. "Moral Relativism Defended", en Explaining Value and other Essays in Moral

THÉMATA. Revista de Filosofía, $\mathrm{N}^{\circ} 48$ julio-diciembre (2013) pp.: 121-133

doi: 10.12795/themata.2013.i48.10 
mo, en los juicios morales hay espacio para ciertas consideraciones moralmente relevantes, que son necesarias en ocasiones para fijar con mayor detalle el contexto particular al que responde un juicio. ${ }^{7}$ Por ejemplo, atender al hecho de que Julia prometió llevar a su hija al cine nos permite dar sentido al juicio "Julia debería llevar a su hija al cine".

Así pues, un juicio moral es aquel que puede desgranarse en la forma“Debe (A, X, M, C"s.

El marco de referencia moral o moralidad, es lo que establece los principios a los que obedecen las actitudes motivacionales y las circunstancias consideradas como moralmente relevantes en determinada comunidad. Esto explica, por una parte, la variabilidad del contenido de los juicios de una comunidad a otra, y el profundo disenso que esta diferencias sustantivas ponen de manifiesto. Son estas diferencias las que llevan a Marlow a sentir, una y otra vez, que los habitantes de las tierras explotadas por su compañía están más allá de los límites de lo humano. Sin embargo, la teoría de Harman explica también la experiencia complementaria, es decir, el inevitable reconocimiento de esas criaturas cubiertas de un halo de misterio como personas. El carácter universal de la forma de los juicios morales permite dar cuenta del reconocimiento de los juicios de los otros como juicios morales, evitando que estos dejen de percibirse como agentes morales. Así como no entender una palabra de lo que alguien me dice en alemán no evita que reconozca a ese alguien como hablante de un lenguaje, puedo reconocer la agencia moral de un sujeto sin necesidad de comprender los motivos morales que lo llevan a actuar de determinada manera. A pesar de que sus juicios morales responden a una red motivacional con contenidos distintos, puedo reconocer en ellos la misma estructura formal que reproducen mis propios juicios. Puedo, por tanto, tomar en cuenta las diferencias entre nuestras moralidades sin verme obligado a desterrar al otro de la esfera de lo moral -y, por ende, de lo humano.

De lo dicho hasta este punto, puede concluirse que Harman explica la ambivalencia que brota del contacto con la alteridad apelando a una versión propia de la distinción clásica entre la forma y el contenido de los juicios morales. De acuerdo con su concepción, los contenidos son muchos, de ahí las llamativas diferencias entre marcos morales de referencia; sin embargo, la forma es

\footnotetext{
Philosophy, Oxford University Press, 2005, Oxford, p. 8-9:

"If S (an speaker) says that (morally) A (an agent) ought to do D (an action), S implies that A has reasons to do $\mathrm{D}$ that $\mathrm{S}$ endorses. (...) if $\mathrm{S}$ says that (morally) $\mathrm{A}$ ought to do $\mathrm{D}$, there are certain motivational attitudes $\mathrm{M}$ which $\mathrm{S}$ assumes are shared by S, A and S's audience."

[7] Ibíd. p. 9

[8] Ibíd. p. 9 : "Formulating this as a logical thesis I want to treat the moral "ought» as a fourplace predicate (or "operator"), "Ought (A, D, C, M)», which relates an agent A, a type of act D, considerations $\mathrm{C}$, and motivating attitudes M."
}

THÉMATA. Revista de Filosofía, Nº48 julio-diciembre (2013) pp.: 121-133 doi: 10.12795/themata.2013.i48.10 
una, y de ahí la posibilidad de identificar la agencia moral de los otros a pesar de dichas diferencias.

\section{Dos premisas relativistas}

El siguiente paso consiste en presentar dos premisas sobre las que descansa la teoría de Harman, para más adelante mostrar en qué sentido puede decirse que su concepción fomenta la adopción de una mirada deshumanizadora hacia la alteridad.

La primera premisa es que la perspectiva desde la cual se puede determinar si los juicios tienen, o no, carácter moral, es una perspectiva que no presupone la implicación del sujeto en un conjunto de prácticas morales. Se trata, por el contrario, de una perspectiva que podemos calificar como "distanciada", en la medida en que podría ser adoptada sin problemas por un sujeto que no ve el mundo con ojos morales.

Parte del atractivo de la teoría reside precisamente en este aspecto, que concuerda con la concepción de la imparcialidad dominante en nuestra cultura y con la concepción de la antropología que se deriva de esta. De acuerdo con esta imagen, adoptar una actitud desapegada con respecto a la alteridad cuando uno interactúa con ella es central para evitar que el discurso antropológico que un sujeto elabora reproduzca prejuicios etnocéntricos. El buen antropólogo reconoce la agencia moral de los otros atendiendo a la forma que manifiestan sus juicios; las reacciones y actitudes que caracterizan su comportamiento moral en el marco de su propia comunidad no tienen un papel determinante en este proceso de reconocimiento. Lo que es más, estas reacciones deben mantenerse en estado de hibernación mientras tiene lugar la interacción con el otro, porque de lo contraria supondrán una fuente de contaminación de la experiencia. En consecuencia, la narración del antropólogo -o, en general, de cualquier recién llegado a una comunidad extraña- debe ser descriptiva en el mismo grado y medida que lo es la narración de un biólogo que estudia una especie animal.

Naturalmente, esto implica que los juicios que expresan censura o elogio moral hacia las acciones de los otros pueden considerarse fuera de lugar, dado que emisor y agente no se sitúan en un mismo marco moral de referencia. Harman afirma que aquellos juicios morales que no son "inner", esto es, juicios dónde el emisor y el agente no comparten una moralidad, descansan en una confusión conceptual'. Así, en la práctica, la teoría de Harman justifica cierta diferencia de trato entre los miembros de nuestra propia comunidad moral y el resto de agentes morales.

[9] HARMAN, G. "Moral Relativism Defended", en Explaining Value and other Essays in Moral Philosophy, Oxford University Press, 2005, Oxford, p. 10

THÉMATA. Revista de Filosofía, $\mathrm{N}^{\circ} 48$ julio-diciembre (2013) pp.: 121-133

doi: 10.12795/themata.2013.i48.10 
La segunda premisa, íntimamente relacionada con la primera, es la autonomía que la teoría presupone entre el hecho reconocer a un agente como moral y la disposición a tratarlo como si lo fuera. Del planteamiento de Harman, se sigue que para reconocer el tinte moral de un juicio y, en consecuencia, la agencia moral del agente al cual se refiere, sólo es necesario identificar tal juicio como una aplicación concreta de la forma "debe (A, X, M, C)". Por tanto, el hecho de que el emisor vea o no susceptible de ciertas formas de trato y no de otras a un agente no es relevante a la hora de determinar si, efectivamente, lo ha identificado como un agente moral.

Existe cierta experiencia común que parece jugar a favor de esta segunda premisa. Por ejemplo, muchas personas enfermas conocen la sensación de haber sido tratadas por un médico exclusivamente qua instancias de una dolencia pendiente de identificación. En estos casos, la interacción entre médico y paciente no está mediada por los ritos que usualmente revisten las acciones que tienen una significación moral: la ausencia de tales ritos pone de manifiesto que el médico no parece preocupado por el enfermo en el sentido relevante. Del mismo modo, algunos administrativos públicos tratan a las personas que utilizan su servicio exclusivamente qua usuarios, olvidándose de su dimensión humana. Estos son casos en que algunas personas son reconocidas como agentes morales por un sujeto sin que, por ello, su interacción con ellas quede impregnada por los valores morales que normalmente se reflejan en su interacción con otras personas.

La conducta de muchos agentes de policía en la Rusia estalinista podría interpretarse como un caso extremo de este mismo fenómeno. Estos agentes fueron capaces de torturar brutalmente a aquellas personas señaladas como "infieles" al régimen sin sentir aversión hacia sus actos. Atendiendo a la conciencia declarativa que tenían sobre sus acciones, no parece haber motivos de peso para afirmar que no reconocían la agencia moral de sus víctimas. ${ }^{10}$

Los tres casos sugieren que es empíricamente posible adoptar sistemáticamente formas de trato que podemos calificar como "amorales" hacia algunas personas sin que ello implique dejar de reconocer su agencia moral, y tal posibilidad parece contar como una razón de peso para confiar en la segunda premisa señalada.

\section{Formas de trato y deshumanización}

Un elemento que tanto el caso del médico como el del administrativo tienen en común, es que presuponen un contexto muy especifico en el que el trato amoral con un agente tiene lugar. En ambos casos, la situación que hace inteligible este tipo de interacción parece estar acotada: una vez ubicado en

[10] GLOVER, J.; Humanidad e Inhumanidad, Ediciones Cátedra, 2001, Madrid, p. 330-332

THÉMATA. Revista de Filosofía, Nº48 julio-diciembre (2013) pp.: 121-133 doi: 10.12795/themata.2013.i48.10 
cualquier otro contexto, el médico que en su quehacer profesional actúa de manera insensible consideraría inadecuado tratar a una persona de esa manera. Esta sensibilidad al contexto, es uno de las principales razones que tenemos para creer que el médico reconoce la agencia moral del agente a pesar de relacionarse con él de forma distante cuando lleva la bata puesta.

En contraposición, la actitud del policía no muestra este tipo de variación en función del contexto. En este caso, la visión amoralizada de la víctima dentro de la cámara de tortura contamina el trato que se le da en el exterior: a pesar del cambio de contexto, su torturador no llega a verla como el tipo de agente con el cual debe establecer formas de interacción de tipo moral y, por tanto, humanas. A pesar de ello, teniendo en cuenta el testimonio histórico de algunos de estos policías, parece que reconocian la humanidad de sus víctimas a pesar de tratarlas inhumanamente. La mayor parte de estas personas identificaban a sus víctimas como "personas", y no puede extraerse de sus declaraciones que pensaran en ellas como criaturas pertenecientes a una raza o especie diferente.

Sin embargo, aquellos que aspiran a comprender cómo atrocidades de este tipo han podido llegar a perpetrarse, se mostrarán perplejos ante la idea de que un sujeto, a pesar de mostrarse perfectamente capaz de reconocer a su víctima como humana, considere que esta merece ser tratada de forma inhumana con total independencia del contexto. Una relectura cuidadosa de un conjunto de experiencias que Jonathan Glover expone en Humanidad e inhumanidad, permite reconocer un fenómeno que sugiere que esta lectura del caso del policía no es, en el fondo, inteligible. Se trata de un fenómeno que nos invita a reinterpretar el caso y afirmar que los agentes de policía del régimen estalinista que participaban en las torturas no reconocían, de hecho, la humanidad de sus víctimas.

El fenómeno al que nos referimos resalta en la cita que abre el capítulo dedicado al nazismo. En ella, Christopher R. Browning se refiere a la intervención del ejército alemán en Polonia en los siguientes términos:

"Sin embargo, una vez comenzó la matanza, los hombres se brutalizaron cada vez más. Como en el combate, los horrores del encuentro inicial terminaron por convertirse en rutina y la matanza resultó cada vez más fácil. En este sentido, la brutalización no fue una causa sino un efecto de la conducta de los hombres". ${ }^{11}$

Si entendemos que cuando habla de "brutalización", el autor se refiere a la adopción de una mirada hacia un agente que lo brutaliza -es decir, que vela su humanidad-, la idea que transmite la cita es que la incapacidad de reconocer a un agente o grupo de agentes como humanos puede ser consecuencia, a la par que causa, de su sometimiento a un trato vejatorio. Glover llama la atención sobre una serie de casos que refuerzan la credibilidad de esta tesis. Entre otras

[11] Ibíd. p. 477,

THÉMATA. Revista de Filosofía, $\mathrm{N}^{\circ} 48$ julio-diciembre (2013) pp.: 121-133 doi: 10.12795/themata.2013.i48.10 
experiencias, señala como primero la permisividad y después la promoción del gobierno nazi de formas de trato humillante hacia los judíos -como la prohibición del uso de transporte público, o la imposición del brazalete identificativos con la estrella de David- jugó un papel decisivo a la hora de posibilitar, con el tiempo, formas de trato radicalmente inhumanas hacia ellos ${ }^{12}$.

Estos casos muestran que cuando se trata a una persona como si no fuera humana, el reconocimiento de su humanidad tiende a erosionarse. En el mejor de los casos, este se vuelve más dependiente de las circunstancias y menos inmediato; en el peor, el agente deja de manifestarse como ser humano.

Este proceso, al que de ahora en adelante, nos referiremos como "espiral deshumanizadora", constituye un claro desafío para aquellos que como Harman parten de la premisa de que el reconocimiento del carácter moral de un agente no depende en absoluto de la disposición a adoptar una forma de interacción moral con él. Los casos señalados apuntan en la dirección contraria: la forma en que se trata a una persona, guía la forma en que se la mira, de modo que ciertas formas de maltrato pueden velar su humanidad. La experiencia de la espiral deshumanizadora muestra que adoptar un trato distintivamente humano con respecto a un agente es constitutivo del propio reconocimiento de su humanidad. La forma en que uno trata a un agente expresa la forma en que uno lo ve. Por este motivo, el que un sujeto no trate a determinado agente como humano, en ausencia de circunstancias específicas que hagan inteligible tal comportamiento, indica que no ha reconocido la humanidad de ese agente.

De lo dicho hasta este punto se desprende que ver como alguien inflinge un acto de crueldad a un agente que identificamos como persona implica experimentar cierto tipo de reacción de rechazo ante él. Ver a la víctima de ese tipo de acto como humana comporta revelarse contra esta conducta, ni que sea en un sentido mínimo, como el de expresar ante terceros un sentimiento de censura. Si, por el contrario, uno se acostumbra a tratar ese tipo de acto como si fuera una conducta perfectamente aceptable -reconozca o no su crueldad declarativamente-, la humanidad de la víctima tenderá a desdibujarse, llegando incluso a desaparecer. Adoptar de un modo sistemático modos de interacción amorales con respecto a un agente moral -hacia lo que este hace y hacia lo que a este le hacen- conlleva dejar de verlo bajo la luz caracteristica de lo humano.

Sin embargo, la teoría relativista de Harman potencia la adopción de este tipo de comportamiento con respecto a los miembros de comunidades con una moralidad distinta de la nuestra. Quizá un ejemplo puede contribuir a iluminar este punto: una turista española pregunta en Tinghir por una dirección y el interlocutor no le responde a ella, sino al hombre que la acompaña. De acuerdo con Harman, parece que una reacción por parte de la mujer que exprese su rechazo hacia esta conducta está fuera de lugar, ya que, desde la

[12] Ibíd. pp. 462-466

THÉMATA. Revista de Filosofía, Nº48 julio-diciembre (2013) pp.: 121-133 doi: 10.12795/themata.2013.i48.10 
perspectiva del interlocutor marroquí, la ofensa que ella experimenta no es inteligible. Desde su marco de referencia moral, el sentido en el que proceder de este modo ante una mujer es una muestra de desconsideración hacia ella es incomprensible. Por ello, la reacción que mejor se ajusta a las circunstancias es una suerte de suspensión del juicio: durante los días, quizá semanas, que pase en las tierras del interior de Marruecos, nuestra turista deberá aceptar este tipo de conducta como si fuera parte del paisaje, y apreciará su idiosincrasia del mismo modo que aprecia la belleza del Atlas o del desierto de piedra caliza.

Lo que nos enseña el fenómeno de la espiral deshumanizadora es que la adopción sistemática de una actitud moralmente neutra hacia la alteridad entraña el riesgo de su progresiva deshumanización. Quizá la adopción esta actitud en el contexto de un breve viaje no resulte especialmente peligrosa, dado que la interrelación con los otros que habitan ese paraje queda fuertemente acotada en el tiempo. Pero desde la perspectiva relativista, la adopción de esta actitud puede extenderse a otros contextos: el turista puede llevarse puesta esta perspectiva a casa y adoptar la misma actitud hacia aquellos que no comparten su moralidad pero cohabitan con él en un mismo ámbito de decisión política o, sencillamente, necesitan relacionarse con él en el día a día para conseguir sus fines. Nada hay en la teoría de Harman que evite la generalización de una perspectiva moralmente distante o desapegada hacia la alteridad.

El problema es que si, en general, sólo podemos considerar que los otros son crueles, honestos o generosos en un sentido puramente metafórico -esto es, si no podemos tratarlos de un modo similar al que solemos tratar a las personas que se comportan de forma cruel, honesta o generosa-, nos convertimos en turistas perpetuos. Lo que podemos aprender de los ejemplos aportados por Glover es que, en estas condiciones, dejaremos paulatinamente de verlos como agentes morales. Si esto es así, el relativismo de Harman no despeja, a fin de cuentas, una vía de escape fiable al peligro de la deshumanización.

\section{Conclusión: a través del cristal}

En la primera sección de esta ponencia, señalamos el rasgo que explica la propensión del universalismo moral a servir de base legitimadora de actitudes y prácticas deshumanizadoras. En el marco teórico universalista, decíamos, la voz del "otro" no es genuinamente escuchada; indiferencia que pone de manifiesto que la ausencia de un auténtico reconocimiento del otro como interlocutor válido.

En un pasaje de "La política del reconocimiento", Charles Taylor traza la diferencia que, a su juicio, existe entre el acto de declarar valiosas las creaciones de una cultura y el acto de equiparar su valor al del resto de creaciones 
culturales "incluso si tales creaciones no son especialmente brillantes"13, una conducta tentadora para los partidarios de una teoría relativista como la de Harman.

En ese fragmento, Taylor rechaza la equiparación generalizada de los productos culturales, amparándose en una queja que se escucha en el seno de algunas comunidades que son objeto de este tipo de política. Los supuestos beneficiarios de la política del reconocimiento, explica, distinguen entre ambas cosas porque quieren respeto, no condescendencia. ${ }^{14}$ La intuición que da sentido a esta exigencia se expresa con claridad:

“'La exigencia de un juicio favorable es absurda. (...) hacer un juicio incondicional en respuesta a una exigencia es un acto de pasmosa condescendencia. Nadie podría considerarlo como un genuino acto de respeto. (...) Objetivamente, un acto de este tipo conlleva desprecio hacia la inteligencia de esa persona: ser objeto de un acto de respeto de este tipo es denigrante" 15

En esta ponencia hemos partido de esta misma intuición, tratando de abrir una vía argumentativa que permita mostrar que tampoco la perspectiva relativista, en sus formulaciones disponibles hasta la fecha, promueve un tipo de interacción con el otro en el que a este le es posible empuñar el papel de interlocutor genuino. La razón que se ha aducido a favor de esta tesis es que, aceptadas las premisas de las que parte el relativista, no hay motivo para exigir a un agente que reaccione a los motivos de la alteridad como si constituyeran una invitación a cambiar su propia forma de hacer las cosas, y, en última instancia, de vivir.

El relativista no ve en la moralidad ajena una forma de vida que lo interpela, que lo obliga a replantearse aspectos de su propio modelo de vida buena. Su teoría no atesora formas de respuesta al encuentro con las prácticas morales que expresen una apertura genuina hacia las razones que las refrendan. Tales formas de respuesta exigen al agente un movimiento de cuestionamiento de las razones que sostienen sus propias prácticas morales que lo lleve a rechazarlas o a reafirmarse en ellas. A la luz de los casos expuestos, he defendido que el reconocimiento efectivo de la humanidad del otro no puede tener sin este movimiento de cuestionamiento.

La experiencia de la espiral deshumanizadora muestra que no es suficiente con ser capaz de identificar palabras en la voz del otro para reconocerla como una voz humana: si se trata sistemáticamente como si fuera ruido, como el temible rugir de un león o el bello zumbar del las abejas, la humanidad de esa voz se desdibuja.

[13] TAYLOR, CH.; "El multiculturalismo y «la política del reconocimiento»", en Argumentos filosóficos, Paidós, 1997, Barcelona, p. 331

[14] Ibíd. p. 331

[15] Ibíd. p. 332

THÉMATA. Revista de Filosofía, Nº48 julio-diciembre (2013) pp.: 121-133 doi: 10.12795/themata.2013.i48.10 
Si, como afirma Clifford Geertz, el universalismo ha constituido un ejercicio de combate o domesticación del dragón de la alteridad, el relativismo no puede verse, en contrapartida, como un esfuerzo honesto de diálogo con ella. Para admirar su belleza sin contaminarla con nuestras propias categorías, el relativista nos invita contemplar al dragón a través de un cristal. Pero, una vez al otro lado de la pared transparente, es inevitable sentir que nosotros no estamos hechos del mismo material que la criatura lejana y exótica que aparece ante nuestros ojos. 